\title{
Safety Benefits of Automated Vehicles: Extended Findings from Accident Research for Development, Validation and Testing
}

\author{
Thomas Winkle
}

\subsection{Introduction}

Advancing vehicle automation promises new opportunities to better meet society's future mobility demands. New, extended concepts for interaction with machines are arising in certain areas [1]. A prerequisite for this is further technological development of assistance systems with more capable sensor and information technologies, allowing for a steady automation of driving tasks in vehicle control, right up to self-driving vehicles [2].

Initially the following meta-analysis documents exemplary investigation of potential safety-enhancing vehicle systems with low degrees of automation. However, a safety prognosis of highly or fully automated vehicles depends on assumptions, as so far no series applications of such features exist. For testing methods in order to develop and validate safe automated vehicles with reasonable expenditure, the author recommends combining area-wide traffic, accident, weather, and vehicle operation data as well as traffic simulations. Based on these findings, a realistic evaluation of internationally and statistically relevant real world traffic scenarios as well as error processes and stochastic models can be analyzed (in combination with virtual tests in laboratories and driving simulators) to control critical driving situations in the future.

T. Winkle $(\bowtie)$

Department of Mechanical Engineering, Institute of Ergonomics, Technische Universität München - TUM, 85747 Garching, Germany

e-mail: winkle@carforensic.com 


\subsubsection{Motivation}

In terms of advancing automation, automobile manufacturers have been offering active steering-assistance systems (Lane Keeping Assistance Systems-LKAS) in combination with adaptive cruise control for series production vehicles since as far back as the turn of the millenium. The combined functionality was available on the Japanese market for right-hand drive vehicles such as the Nissan Cima (2001) and the Honda Inspire (2003). When using both assistance systems, short-term, partially automated driving (see Sect. 17.1.2) of up to 20 seconds was possible under the supervision of the driver (author's test drives in 2003). Since 2008, German manufacturers, starting with the VW Passat CC, have also been selling active steering systems optionally in selected models [3]. Opportunities for greater traffic safety increase with rising vehicle automation. Further market penetration of standard equipped safety-enhancing driver-assist systems will lead to a further reduction in road accidents (see p. 344, Sect. 17.4.1).

According to figures from the Federal Statistical Office of Germany, 3475 people were killed in road accidents in Germany in 2015 [4]. On average around nine people a day lose their lives in this way on German roads alone. Among these accidents are some that can be prevented by automated vehicles in future. A potential safety benefit can be determined on the basis of accident data. The examples given in this article demonstrate the possibilities and limits of analyzing this data. What is meant here by potential safety benefits is the predicted fall in accident-related damage. Prerequisites in order to determine specific potential safety benefits are basic assumptions about the overall traffic situation and about the proportion of automated driven mileage with its corresponding functional limits.

Traffic accident research is carried out worldwide by various organizations. Their research encompasses the subfields of accident surveys/-statistics, accident reconstruction, and accident analysis [5]. Accident investigation, carried out by the police in all federal states, forms the basis for accident research in Germany. Furthermore, other institutions such as the Traffic Accident Research Institute of TU Dresden GmbH (Verkehrsunfallforschung, or VUFO) and the Hannover Medical School, as well as vehicle manufacturers and the German insurance industry, all carry out their own accident research. Central to this is investigating accidents directly at the scene, statistically recording and analyzing them according to certain characteristics, and, where needed, using this to further develop future vehicle automation. Regarding automated vehicles' potential safety benefits, the following elaboration exemplarily demonstrates potentials, limits of findings and predictions given by accident-data collections.

The following questions will be discussed, using specific examples from accident research:

- What significance do analyzes and findings from road-accident research hold for the introduction of automated vehicles?

- How can the potential safety benefits of automated vehicles be established? 


\subsubsection{Categorizing the Levels of Driving Automation}

Three categories for levels of driving automation (concerning the degree of vehicle guidance) are outlined briefly below, and will later be used as examples to illustrate the potentials and limits of accident data analysis. For use in subsequent sections here the categorization of the previous BASt-project group "Legal consequences of an increase in vehicle automation" [6] published in 2012 is sufficient. These five degrees of automation begin with the original conventional vehicle guidance, termed "driver only", where the driver is permanently responsible for the vehicle's longitudinal and lateral motion. The gradations continue with driver assistance ("assisted") and partial automation ("partially automated"), with constant driver supervision at all times. Lastly, the levels of high automation ("highly automated") and full automation ("fully automated") permit humans to stay out of the vehicle-guidance process some or all of the time [6].

Another five levels were also defined by the American NHTSA agency [7]. Subsequently the SAE International, formerly the Society of Automotive Engineers, developed further six distinctions, as described in its J 3016 informational report. They are being increasingly used in today's research projects. These levels correspond precisely to the BASt levels published previously in 2012, with two key differences. First, the names are different. Second, SAE adds level 5 (full automation), at which the automated driving system performs the entire dynamic driving task under all conditions that can be managed by a human driver [8] (see below Fig. 17.1).

\subsection{Accident Data Collections to Demonstrate Potential Safety Benefits}

According to accident statistics, a fatal road accident occurs on average:

- every $2.7 \mathrm{~h}$ in Germany

- every 25 min (ca. 34,000 annually) in the USA

- every $26 \mathrm{~s}$ (at least 1,240,000 annually) worldwide [4, 9, 10].

Since the early 1970s, measures taken in road building, legislation, the rescue chain, emergency medicine, and passive and active vehicle safety have lowered the numbers of

\begin{tabular}{|c|c|c|c|}
\hline $\begin{array}{c}\text { Fully automated } \\
\text { Highly automated } \\
\text { Partial automated } \\
\text { Assisted } \\
\text { Driver only }\end{array}$ & $\begin{array}{c}\text { Level } 4 \text { - full self-driving automation } \\
\text { Level } 3 \text { - limited self-driving automation } \\
\text { Level } 2 \text { - combined function automation } \\
\text { Level } 1 \text { - function specific automation } \\
\text { Level } 0 \text { - no automation }\end{array}$ & 10 & $\begin{array}{l}\text { Level } 5 \text { - full automation } \\
\text { Level } 4 \text { - high automation } \\
\text { Level } 3 \text { - conditional automation } \\
\text { Level } 2 \text { - partial automation } \\
\text { Level } 1 \text { - driver assistance } \\
\text { Level } 0 \text { - no automation }\end{array}$ \\
\hline$\Rightarrow \mathbf{B}$ & $\Rightarrow$ NHTSA & & $\Rightarrow$ SAE (J 3016) \\
\hline
\end{tabular}

Fig. 17.1 Levels of automation according to BASt, NHTSA and SAE. Image rights: Author 
injuries and fatalities in road accidents considerably in Western countries. This finding is based on large-scale worldwide collected surveys and analyzes of road accidents with various orientations, amount of data and from surveys of varying depth. Selected accident-data collections that exemplify on automated vehicles' potential safety benefits will now be introduced, along with their respective pros and cons.

\subsubsection{Federal Road-Traffic Accident Statistics in Germany}

In accordance with Section 1 of the StVUnfStatG ( $\$ 1$, German law on statistics of road traffic accidents) from 1990, the Federal Statistical Office of Germany in Wiesbaden publishes monthly federal statistics on fatalities, injuries, and property damage. All police stations are obliged to submit defined records of reported accidents, and to pass on information from traffic accident reports to state-level statistics offices [4].

The nationwide statistical data is published regularly on the Internet. The cause of accident determined by police investigation, which essentially evaluates drivers' driving errors, shows the potential for automated driving (see p. 344, Sect. 17.4.1.1; p. 351, Sect. 17.4.3.2). All documented information is subdivided into clear categories, e.g. type of road, age of all parties including the people causing the accident, and type of transport means. There is no specific documentation on accident reconstruction, injuries or vehicle details available.

\subsubsection{German In-depth Accident Study (GIDAS)}

Extensive data is required for the detailed and statistically reliable analysis of road-accident scenarios. In Germany, the database of GIDAS (German In-Depth Accident Study) is qualified for many of these purposes. Nationally and internationally recognized, it is considered one of the most comprehensive and significant accident databases in the world $[5,11]$. In-depth analysis at the accident location follows an incidence of personal injury involving any type of vehicle, and has been supported in Germany by the Federal Highway Research Institute (BASt) since 1973 and the Research Association of Automotive Technology (FAT) since 1999. Today, the GIDAS project anonymizes and places in a separate database some 2000 accidents annually, with up to 3000 coded parameters, from the survey areas of Hannover (since 1973) and Dresden (since 1999). Each documented accident contains information on the environment (e.g. weather, road type, road condition, environment), the situation (e.g. traffic situation, conflict situation, and type and manner of accident), the vehicles (type, safety equipment), and personal and injury data including a sketch of the accident with reconstruction and image data $[5,11,12]$.

The benefits of the GIDAS data are based on in-depth analyses with several types of vehicles causing injury to persons, the related accident site, and the field of medicine. To aid further analysis, many cases are reconstructed and simulated electronically to a high 
level of detail with the PC-Crash simulation software from the Austrian company DSD-Datentechnik www.dsd.at [13]. One disadvantage lies in the fact that data access is limited to car manufacturers and component suppliers taking part in the project. The investigation criteria only include accidents involving injuries. Although only the Hannover and Dresden areas are surveyed, the results are transferable to the whole of Germany via extrapolation (in technical terms: weighting and comparison with official accident statistics, see Sect. 17.2.1).

\subsubsection{Road-Traffic Accident Statistics in the USA}

In the USA, the National Highway Traffic Safety Administration (NHTSA) has been consistently documenting every fatal road accident since 1975 using the Fatality Analysis Reporting System (FARS) [9]. Furthermore, the National Automotive Sample SystemCrashworthiness Data System (Nass-CDS) has existed in the USA since 1979 [14]. The program analyzes road accidents involving personal injury or severe property damage using interdisciplinary teams, similarly to the German GIDAS project.

In-depth data collections for extended accident analysis can also be found in the USA, although, unlike GIDAS, they offer no reliable accident reconstruction. For example, it is not possible to assess emergency braking functions [11]. Accident risks in the USA differ, e.g. due to the longer distances driven. The drop in US traffic accident fatalities since 1970 is lower, at around $16 \%$, than in Germany, at around $60 \%[4,9]$.

\subsubsection{Road-Accident Data in Asia, Taking the Examples of China and India}

Traffic accident data collection in Asia is still in its initial stages. Analysis is superficial and permits no reliable reconstruction. While initial approaches to reliable data collection have been made in China, the number of traffic accident fatalities is not even recorded in India [11].

\subsubsection{International Road-Accident Data Collections}

The International Road Traffic and Accident Database (IRTAD) consists of a collection of various national official accident statistics. It includes road accidents involving personal injury generally as well as fatalities - distinguished by age, location and type of road use - and is maintained by the Organisation for Economic Co-operation and Development (OECD) in Paris. Besides the countries bordering Germany, it contains data from: Australia, Canada, Finland, Greece, Hungary, Iceland, Ireland, Israel, Italy, Japan, Luxembourg, New Zealand, Norway, Portugal, Slovenia, South Korea, Spain, Sweden, the UK and the USA [10]. 
The data is publicly accessible on the Internet and especially suited to comparing the data between countries included. It is possible to study the impact of various regulations and collective driving behavior (north vs. south, for instance). In-depth information on the details as to how the accident occurred is still lacking, however. Moreover, survey methods and data volumes vary from country to country.

Another initiating action for harmonisation of global in-depth traffic accident data is the Initiative for the Global Harmonisation of Accident Data (IGLAD). IGLAD was initiated in 2010 by European car manufacturers to improve road and vehicle safety. The database contains accident data according to a standardised data scheme. This should enable comparison between datasets from different countries. The first phase of the project was funded by the European Automobile Manufacturer's Association (ACEA). The growing data set of the second phase, which started 2014, contains 93 variables regarding the accidents, roads, participants, occupants and safety systems. Limited data (between 50 and 200 cases, data years 2007-2012) from each of 11 countries (Australia, Austria, China, Czech Republic, France, Germany, India, Italy, Spain, Sweden and USA) are available for research.

\subsubsection{Accident-Data Collections of Auto Manufacturers}

In order to collect findings on accidents involving current vehicles, and to fulfill product monitoring obligations, interdisciplinary expert teams from car manufacturers and component suppliers today carry out accident analysis at the scene together with hospitals and the police. The results primarily serve continuing improvements in the effectiveness of vehicle safety systems currently in use.

Moreover, the analysis of accident incidents by the manufacturer serves in complying with mandatory duty of care and observing potential product dangers that may arise during use. According to Section 823 of the German code of civil law (BGB), an auto manufacturer is liable for errors of its products' consequential damages arising from intended or foreseeable use by the driver or other persons. A car manufacturer must therefore collect and analyze information on vehicle use and innovative systems. The more dangerous a product is, the greater the obligation to protect and monitor a product's safety in and after the development process [15], (see Chaps. 21, 23 and 28).

Among the car manufacturers Mercedes-Benz (now: Daimler AG) began investigating road accidents involving its Mercedes vehicles together with the police of the district of Böblingen as far back as the late 1960s. Two years later, Mercedes' accident research had, with ministerial permission, access to regular telephonic information and insight into the accident files of the police in Baden-Württemberg. Since at least the 1970s, other manufacturers such as BMW have been studying and recording collisions involving their own vehicles on a larger scale. Volkswagen began cooperating with the insurers association Haftpflicht-, Unfall-, Kraftversicherer-Verband (HUK-Verband) in the late 1960s and with 
the Hannover Medical School MHH (the predecessor of GIDAS) starting from 1985. Volkswagen has been recording its own data since 1995 [11].

In-depth, interdisciplinary analysis of accidents by car manufacturers involving new types of vehicles with the latest safety technology and especially involving function developers enable clear insights into the potential benefits of driver-assistance systems. However, around a few hundred cases per year exclusively involving a brand's own vehicles are not comparable with GIDAS data in terms of their statistical validity.

\subsubsection{Accident Data of the German Insurance Association}

The German Insurance Association (Gesamtverband der Deutschen Versicherungswirtschaft - GDV), the successor organization of the HUK-Verband, has at its disposal documented information on incidences of damage from motor claims of German insurers where compensations for damages based on contracts were paid. These data benefit the GDV for example in grading insurance contracts, or in determining the potential safety benefits of driver-assistance systems [16].

Accident research by insurers has access to all cases of motor-vehicle liability losses reported with the GDV. Unfortunately, the data are not open to the public. Accident analysis does not take place at the scene and the accident-recording criteria are not comprehensive. Moreover, the insurer's interest in the particularities of a case ends as soon as it sees liability to pay. This therefore means that there is only little detailed information on the cause of undisputed cases. In single-vehicle accidents with only one party involved, such as so-called driving accidents, when a driver loses control of the vehicle, there is mostly no data available on the cause [11].

\subsubsection{Accident-Data Collections of Consumer Associations (ADAC)}

ADAC (the German automobile club) has been carrying out accident research since 2005 . It is a cooperation project between ADAC air rescue and the ADAC technology center. From rescue flights, information on around 2500 severe accidents nationally is collected in the ADAC database annually. The accident data is sourced from the police, doctors, fire service, and motor-vehicle assessors [17].

The ADAC accident data contains information on road accidents with seriously injured persons. They include aerial pictures with a vehicle's final position and a detailed medical diagnosis. Supplementary individual assessment is possible using the files, although the data is not publicly accessible. There is no concluding interdisciplinary reflection with the respective persons investigating the accident. 


\subsection{The Fundamentals of Accident-Data Analysis}

\subsubsection{Level of Data Collection Versus Number of Cases}

The validity of accident data regarding potential safety benefits varies considerably depending on the collection method. In-depth surveys are mostly carried out in cooperation with qualified interdisciplinary teams. Particularly well-founded results are achievable when function developers, accident analysis experts, doctors, and traffic psychologists work together on analyzing individual cases. But this level of data collection is usually restricted to a low number of cases, hampering its statistical validity.

Evaluations from accident databases indicate which measures are needed to increase traffic safety. A detailed accident analysis including an accident reconstruction encompasses a retrograde calculation of speeds from traces of the accident, an investigation into how the accident arose, a check for accident fraud, consideration of how avoidable it was, and biomechanics. An evaluation of future systems' potential benefits based on this requires extensive knowledge of the given conditions and framework.

Until now, forward-thinking ideas on improving vehicle safety have primarily come from combining accident analysis, existing experience and extensive research work. Accident research is one way to determine the efficiency of existing automated vehicle functions and the need for new safety-enhancing ones. In what follows, basic terms of accident-data evaluation are explained.

\subsubsection{The Validity of Areas of Action Compared to Areas of Efficiency}

When comparing various accident-data analyses, both the way in which data is collected and the way it is processed must be distinguished. Frequently, areas of action adopted under optimal conditions are confused with areas of efficiency under real conditions.

An area of action covers the accidents that a system can influence. The area of action can vary depending on how precise a system's specification is defined. As a result it is an initial estimation for the maximum achievable potential of the regarded level of automation. The actual resulting efficiency of a function, on the other hand, is usually significantly lower. Efficiency here is the effect that a specified system actually has. It is either proved in the occurrence of accidents (a posteriori) or predicted by a simulation (a priori).

Determining an area of efficiency thus demands precise knowledge of two factors:

- the system specification with its corresponding function limits

- the driver's behavior.

The degree of efficiency describes a function's relative efficiency as a percentage and is always dependent on the unspecified term of the area of action [18]: 


$$
\text { degree of efficiency }=\frac{\text { area of efficiency }}{\text { area of action }}=x[\%]
$$

\subsubsection{Potential Safety Benefits Depending on the Level of Automation and Degree of Efficiency}

Some analyses of potential safety impacts using accident databases examine the maximum assumed area of action described above. In contrast, analyzing the degree of efficiency comes closer to reality by assessing an area of efficiency for its actual benefit [18]. The resulting safety benefits of automated vehicles only arise, though, after all risks have been taken into consideration. The benefit complies with the reduction of accident frequency and severity. New risks exist in terms of as-yet nonexistent accidents that may arise with increasing automation.

The theory of inventive problem solving (TRIZ) defines the requirements of an ideal machine by the formula of an ideal final result with an unlimited benefit without costs and damages [19]:

$$
\text { ideal final result }=\frac{\sum \text { benefit }}{\left(\sum \text { costs }+\sum \text { damages }\right)}=\frac{\infty}{(0+0)}=\infty
$$

On the one hand, when looking at the actual total consumer-relevant potential as regards the safety benefit of automated vehicles, this increases in accordance with the degree of efficiency up to the maximum area of efficiency (proof by accident data analysis and knowledge of functions). On the other hand, the risks may increase in line with the level of automation ("Driver" vs. "Robot"). These in turn reduce the actual safety benefit (see Fig. 17.2). To minimize potential risks, manufacturers carry out risk management (see Chap. 28) that takes accident data into account.

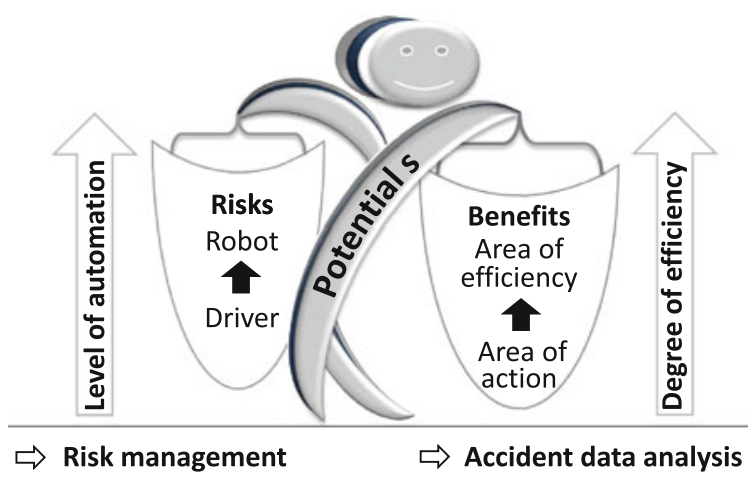

Fig. 17.2 Consumers evaluate the potential safety benefits subjectively by weighting up the perceived risks and benefits in the relevant contexts. Risks depend on the level of automation, benefits on the degree of efficiency. Accident-data analysis and risk management (see Chap. 28) allow for objectivation (see Chap. 30) and optimization. Image rights: Author 


\subsection{Significance of Possible Predictions Based on Accident Data}

Using examples, the following meta-analysis shows what is and is not possible when drawing conclusions about potential benefits on the basis of various accident data. As there is no existing experience of analyzing highly and fully automated vehicles, systems without automation ("driver only"/"no automation") or with low levels of automation referring to the main driving task ("assisted"/"partially automated") are considered first, divided into a-posteriori- and a-priori-analyzes.

Section 17.4.1 describes examples of a-posteriori-statements on accident data collected so far. In the definition used here, figures "gained from experience" [20] can be used directly for interpretations. In contrast, the a-priori-forecasts defined in Sect. 17.4.2 are based on accident-data collections to assess the potential benefits of future levels of automation, exclusively using assumptions “obtained by logical reasoning” [20].

\subsubsection{A-Posteriori-Analyzes of Accident Data for "Driver Only"/ "No Automation"}

Past and present a-posteriori-analyzes of accident-data collections with conventionally (human-) driven vehicles form the basis for direct insights into accident black spots and changes in real-life traffic accidents. In this "driver-only"/ "no-automation" category, there are neither warnings nor interventions in longitudinal and lateral guidance on the basis of environmental sensors.

To illustrate this, the change in the numbers of accident deaths serves as one example (see Sect. 17.4.1.1), the impact of Electric Stability Control, or ESC, is another (see Sect. 17.4.1.2).

\subsubsection{Traffic Statistics: Accident Fatalities Versus Registered Motor Vehicles}

One example of what currently available accident data can show is the relationship of traffic accident deaths to vehicles registered, taken from data of the German Federal Statistics Office. This demonstrates that numbers have been dropping in Germany since the dramatic figure of 21,332 traffic accident fatalities in 1970 [4].

In short, the accident data shows that the number of traffic fatalities dropped from over 21,000 in 1970 to almost 3000 per year - at the same time as increases in registered vehicles occurred. The multifarious causes of this lie in the area of various legislative, technological, medical, and infrastructural measures (see Fig. 17.3). The overlapping of all safety measures makes it difficult to prove the effectiveness of any single potential safety benefit. 


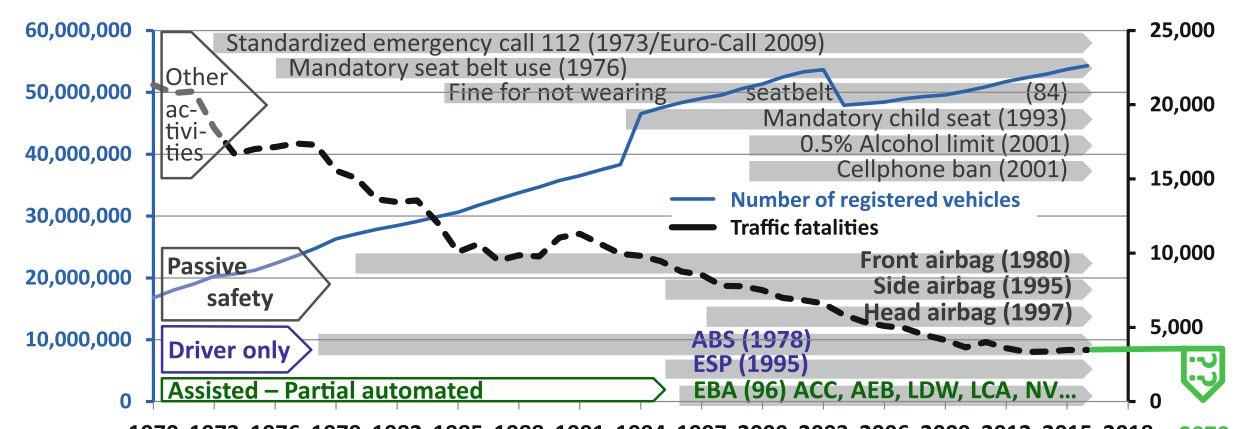

Fig. 17.3 Reduction of traffic fatalities due to safety enhancements despite increase of registered motor vehicles in Germany. Image rights: Author

\subsubsection{Studies on the Effect of "Driver-Only"/"No-Automation" Systems}

Electronic Stability Control, or ESC, introduced in 1995, is technically built up on anti-lock braking, or ABS, introduced in 1978. It uses that system's wheel speed sensors together with additional sensors for yaw rate, steering wheel angle, and lateral acceleration. Using the information from these sensors, ESC tries to stabilize the vehicle in case of a recognized skid by independently braking individual wheels. With this braking intervention, ESC can convert a lateral collision into a less vulnerable frontal crash. In 2001, Daimler accident research assumed that $21 \%$ of skid accidents resulted in injuries and $43 \%$ in fatalities [21]. The findings of accident-research experts investigating individual cases on behalf of vehicle manufacturers diverged greatly at that time. Later predictions of potential benefits based on larger amounts of data also differ. Areas of action from the year 2000 , for instance, show a positive impact of up to $67 \%$ for severe accidents due to skidding [22]. Other studies found that ESC provides the second-most effective increase in safety in the "driver-only" category, after the introduction of safety belts as a passive safety system [2]. The proportion of accidents caused by driver-error and skidding, for example, fell after the introduction of ESC as a standard in all Mercedes-Benz cars from about 2.8 involved cars (per 1000 registered in Germany) in 1998/1999 to 2.21 involved in 2000/2001. ESC's high effectiveness could also be verified in other car brands such as Volkswagen, where accident statistics show lower accident frequency and prevention of especially critical accident types [22].

In summary, safety benefits can already be proven today for safety-enhancing "driver-only" functions with quick market penetration depending on various data sources and suppositions. Particularly for ESC, safety impacts can be well-founded scientifically verified. 


\subsubsection{A-Priori-Forecasts for Assisted and Partially Automated Driving}

A-priori-forecasts are tied to hypotheses and inferences. Assisted and partially automated driving functions, for example, can save the driver from imminent danger via optic, acoustic or haptic warnings or short braking or steering interventions with a warning character. A prerequisite for successfully averting danger, however, is the assumption that the driver will react in time and appropriately to the traffic situation.

From a technical point of view, these advanced levels of automation - with extended computer and sensor technology for environmental perception-allow for increasingly capable assistance systems. Some safety-enhancing driver assistance systems on the market today give warnings when there is recognized danger in parallel and crossing traffic. These include collision warning systems as EBA-Electronic Brake Assist, ACC with FCWS - Adaptive Cruise Control with Forward Collision Warning System, LCALane Keep Assist, LDW-Lane Departure Warning, NV-Night Vision or intersection assistance. Other systems intervene in the longitudinal and lateral vehicle dynamics, such as Electronic Brake Assist (EBA) or Autonomous Emergency Brake (AEB), (see Fig. 17.3).

\subsubsection{Study on the Potential of Lane Departure Warning}

One approach to analyzing road accidents together with doctors, psychologists and development engineers was introduced in 2006, using the example of a Lane Departure Warning (LDW) system [24]. The results, achieved with the participation of the author of this paper, a psychologist, and a function developer, were based on an interdisciplinary research community between a car manufacturer, a university hospital, and the police, with support from the Bavarian Ministry of the Interior, Building and Transport (BStMI).

Such interdisciplinary analyzes of accident causes and consequences include examining the technical, medical, and psychological details by experts from each field, then integrating all results collectively. Today, for instance, driving-related psychological data is increasingly collected to analyze a road accident. Using standardized interviews, the experience of a collision is recorded and evaluated from the driver's point of view. Technical reconstruction of the accident is supplemented by a traffic-related psychological perspective.

In coordination between the professional teams, taking the example of Lane Departure Warning, it was explained what specifications of the system design had to be met. Specific focused questions from the technological development allow the selected accidents to be filtered further. This gives insight into the accident-avoidance potential of the systems under development. For this purpose, knowledge of the system's specific technical limits is crucial. Recommendations for further functional system enhancements are also possible [24].

In conclusion, these detailed accident analyzes show the benefit of comprehensive accident-data collection. Within this study, experts on technology, medicine, and 
psychology were closely interconnected. The interdisciplinary approach delivers numerous additional references in terms of vehicle details, accident scenes, parties involved in accident, injury patterns and witness statements. This extra information provides insight into active steering corrections, interventions of the brakes and reactions immediately preceding a collision, as human errors such as fatigue, inattentiveness or distraction are the main causes of lane departure. Various directions from which an interdisciplinary team analyzes the accident allow the computer-aided reconstruction and simulation of an incident to be highly realistic. To determine representative findings from this, however, it is necessary to validate it with larger accident-data collections.

\subsubsection{Interdisciplinary Degree of Efficiency Analysis Based on Current Driver Assistance Systems}

Building on the advantages of interdisciplinary analysis of the effectiveness of Lane Departure Warning, a further interdisciplinary degree-of-efficiency analysis was carried out four years later. The objective was to compare available safety-enhancing driver-assistance systems which were available on the market. This study used a sample of reconstructed accidents $(n=100)$ in close consultation with the respective function developers. Therefore an interdisciplinary accident-data evaluation was carried out by the author together with a psychologist. Regarding accident causes, the driver assistance systems' effectiveness at avoiding accidents depending on the situation was analyzed [25]. The range of systems available for study in early 2010 included Night Vision, Lane Departure Warning, Lane Change Assistant and Adaptive Cruise Control. To establish the degree of efficiency, accident research data, weighted according to accident statistics for Bavaria, was analyzed. In the process, real-life accidents were compared with the reconstructed accident scene, and the accident cause was assessed in terms of human-machine interaction. This was done in line with the human-machine interactions described in the ADAS Code of Practice for the development of Advanced Driver Assistance Systems (ADAS) with active longitudinal- and lateral guidance [26]. After many years of preparation [27, 28] it was published by the European Automobile Manufacturer's Association (Association des Constructeurs Européens d'AutomobilesACEA) in 2009 [29]. The potential for preventing accidents was only deemed to be positive if every development expert for the relevant system agreed. The results showed that the examined systems could significantly contribute to reducing the severity of accidents.

Overall, the study predicts that the investigated driver assistance systems would positively impact accident prevention, with a $27 \%$ drop in the total number of injured persons. The number of injured would thus be reduced from 126 drivers and 49 passengers to 94 and 33 respectively. It should be kept in mind that the results assume optimal reactions in terms of human-machine-interactions. This would need to be verified by studies with test persons before drawing final conclusions. Further, $100 \%$ distribution of the systems, operating error-free within the system limits, would have to be assured. 
The injury grading adopted was based on the Abbreviated Injury Scale (AIS) [30], as also used in ISO 26262 for functional safety [31]. The AIS codes every injury to the human body with a numerical value between 1 (light injuries) and 6 (extremely critical or fatal injuries). The most severe injury of all individual injuries of one person is thus defined as MAIS (Maximum AIS). An uninjured person is classified with MAIS 0.

Analyzing accident causes further revealed that more than $60 \%$ of them involved so-called information errors-malfunctions of information access and information reception. This explains the correspondingly high effectiveness of warning assistance systems [25].

In summary, currently available driver assistance systems were compared in an interdisciplinary study, with the respective developers taking part in the analysis. Each individual developer knows the specific relevant function parameters of his system, thus allowing for more accurate assessments of potential benefits. It has to be noted that the sample of 100 cases in the area-of-action study, weighted in comparison with representative accident data from Bavaria, is too small to provide statistically reliable statements based on the results obtained. However, it is possible to derive a tendency where these driver assistance systems contribute substantially to road safety.

Attention should be drawn to the fact that there are further options for obtaining statistical evidence to the forecast safety gains of braking assistance and automatic emergency braking functions. In addition, there are assessment methods for forecasting safety benefits based on simulations using software-based accident reconstructions [32].

\subsubsection{GIDAS Database Analysis for Potential Safety Benefits of Connected Vehicles}

Based on a larger data volume, the following analysis of the German In-Depth Accident Study (GIDAS) database shows the complexity and variety of several assumptions. Together with a team of experts, the author carried out this analysis with a more significant sample in 2009 as part of the Safe and Intelligent Mobility-Test Field Germany (Sichere Intelligente Mobilität: Testfeld Deutschland-simTD) research project. The objective of the analysis was to assess the potential benefit of future safety-relevant vehicle communications systems. Functions for connected systems with a direct safety impact on road traffic were considered. The underlying data encompassed 13,821 accidents involving personal injury documented by GIDAS from 2001 to 2008 in the areas of Dresden, Hannover, and their surroundings [12]. To extrapolate this for the whole of Germany, the data acquired in the statistical sampling scheme was weighted using accident statistics from the German Federal Statistical Office. These official statistics contain all accidents involving personal injury registered in Germany over the calendar year. In 2007, for instance, there were 335,845 road accidents involving personal injury [4].

The variables needed for the analysis were precisely defined in several consultations with the simTD function developers and accident experts from Audi, BMW, Bosch, Daimler and Volkswagen. All project participants agreed to begin by analyzing 13 safety-related warning functions. The participants jointly decided to look at relevant 
vehicles such as cars, trucks, buses, agricultural tractors, rail vehicles (including trams and city railways, but no Deutsche Bahn trains) and motorbikes (motorized two-wheelers, three-wheelers, quad bikes from $125 \mathrm{cc}$ ) in the course of several workshops. This was followed by very intensive work to determine the areas of action using the extensive GIDAS data. This selection was initially made by taking the variables from all accidents relevant to each system relating to the complete accident occurrence. It showed that the areas of action for each individually examined function varied in a wide range between 0.2 and $24.9 \%$. Areas of action can thus only give an estimation of the maximum effectiveness that cannot be exceeded with great certainty. It should also be noted that it is not possible to add up individual areas of action, due to their overlapping between functions.

In a subsequent degree of efficiency analysis, three assumed function types (electronic brake light, cross-traffic assist, traffic-sign assist for stop signs) from the GIDAS area of action analysis described above were selected. The corresponding degrees of efficiency were adopted by using a reduced sample of driving simulator investigations.

For accidents avoided by the driver with cross-traffic assist (see [33]), for example, there was a sizeable range, from 9.9 to $73.3 \%$. This results from both varying driver reaction times and different braking intensity upon warnings. Therefore, three reaction times $(0.54,0.72$ and $1.06 \mathrm{~s})$ and the respective probabilities of their occurrence were determined. Furthermore, in the cases of unsuccessful reactions, weak braking of $50 \%$ of maximum braking pressure was assumed and $100 \%$ for successful reactions [12].

In summary, this sophisticated approach to analyzing degrees of efficiency was aimed at determining and evaluating with statistical relevance the potential of future, connected, safety-enhancing driver-assist functions. The range between $10 \%$ and $70 \%$ that was found, however, diminishes the validity and thus only permits tendencies and outlooks concerning accidents avoided. This wide scattering is rooted in the sensitivity of the parameters descried above and the warning algorithm in question, as drivers' reaction times and braking intensities differ greatly in practice.

\subsubsection{Potential Safety Benefits and Test Scenarios for Development of Highly and Fully Automated Driving}

\subsubsection{GIDAS Databased Expert Estimates until 2070}

From a technical point of view, automated vehicles today can already autonomously take over many driving tasks in moving traffic under favorable conditions. While driver assistance systems support the driver, the advanced systems like highly and fully automated driving temporarily or permanently take over the driving tasks.

Among others highly and, particularly, fully automated driving is designed to approach "Vision Zero". The aim is to travel as accident-free and effectively as possible. Roads and means of transportation should be designed in such a way that no person is killed or severely injured. The vision of being accident-free has its origins in occupational safety and was first applied to road traffic in Sweden in the 1990s. The EU has supported projects 
for automated vehicles such as the "Highly Automated VEhicles for intelligent transport" (HAVEit) research project, which was sponsored by the EU with 17 million Euros. Car manufacturers such as BMW, Daimler and Volkswagen/Audi are also working on visions of accident-free driving. Prof. Dr. Thomas Weber, member of the Board of Management of Daimler AG for research and development, explains in an interview:

Unser Weg zum unfallfreien Fahren treibt uns an, die Mobilität auch in Zukunft für alle Verkehrsteilnehmer so sicher wie möglich zu gestalten. [21]

(Our 'path to accident-free driving' also drives us to design mobility as safely as possible for all road users in the future.)

The number of road accidents involving personal injury with a car as the main cause fell in Germany in the first decade of this century, from 266,885 in 2001 to 198,175 in 2010. According to the Federal Statistical Office (2010), cars are the main cause of road accidents, at $68.7 \%$. The accident types mainly break down into the following categories: Turning at/Crossing intersections $(58,725)$, Parallel traffic $(44,812)$, Turning $(33,649)$ and 30,737 Dynamic accidents [4] (see Fig. 17.4).

Until now, there has been no empirical proof of the overall safety gains of fully automated driving functions. One of the first comprehensive forecasting models in vehicle-safety and accident research was published by Daimler. It investigated automated vehicles' potential for accident prevention by means of assumed deployment and market penetration scenarios. These were based on expert estimates, third-party forecasts and GIDAS data. The forecast, which is able to provide an initial rough estimate, is based on a total of 198,175 preventable collisions caused by cars in 2010 (see Fig. 17.4). The assumptions involve changes within each accident type (Parallel traffic, Stationary traffic, Pedestrians, Turning at/Crossing intersections, Turning, Dynamic accidents). It can be seen, for example, that accidents involving a car losing control or in parallel traffic will fall by around $15 \%$ by 2060 with increasing automation, while accidents when turning at or crossing intersections will proportionately increase by around $10 \%$ [34].
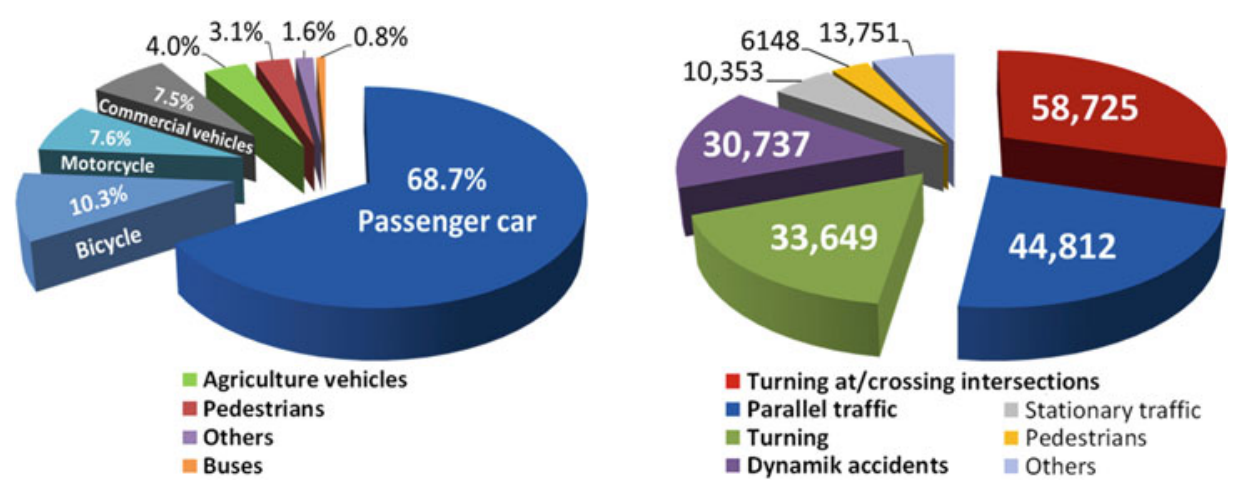

Fig. 17.4 Passenger cars as main cause of road accidents and distribution of accident types. Source Federal statistical office-DESTATIS, GIDAS. Image rights: Author 
According to these estimates for increased automation, an overall reduction of $10 \%$ of accidents would be achievable by 2020. In years thereafter, reductions would be achievable of $19 \%$ by $2030,23 \%$ by $2040,50 \%$ by $2050,71 \%$ by 2060 and almost total prevention by 2070 [34]. The forecast thus indicates that a car in 2070 will cause almost no accidents, but will be able to sustain serious collisions. It can certainly be assumed that an automated vehicle will be able to avoid some collisions that a third party would have caused. It has to be kept in mind, however, that this study does not consider accidents caused by other road users. Potential technical failures (see Fig. 17.6) are also not included. In addition, the data used from the German Federal Statistical Office, and above all the validity of GIDAS, mainly centers around crash and post-crash statements with injured people (see [35]).

\subsubsection{Global Accident Data Evaluation for Relevant Traffic Test Scenarions}

For a complete overall evaluation of highly- and fully automated vehicles' active safety, the author would also recommend incorporating findings concerning worldwide accident data collections as well as analysis with no harm to people, near collisions, traffic simulations and weather data. Therefore a first-time comprehensive area-wide study based on all police reports was carried out (see Fig. 17.7). The findings can be completed with information from hospitals, insurance companies and models of human behaviour. Knowing all relevant factors that may lead to a collision, virtual simulations can be performed based on detailed and quantitative models. Possible system responses can be classified in true positive (or negative) and false positive (or negative). The evaluation of automated safety functions has to consider all possible system responses [36].

The purpose is to comprehensively link up all international known collisions using geographically defined road-accident data and the accompanying high-definition geographic digital mapping data (e.g. Google Maps, Nokia HERE, TomTom, OpenStreetMap) with traffic data from different sources (e.g. cars, mobile phones, road traffic devices). Localized accident data in the states of the USA, for example, exist via www. saferoadmaps.org. Similarly, the British government publishes details on www.data.gov. uk; these are in turn located on the UK Road Accident Map. Regional accident data in Germany (updated monthly) can be gathered from police software-supported IT applications - in some federal states from the Geographic Positioning, Analysis, Representation and Information System (Geografisches Lage-, Analyse-, Darstellungs und Informationssystem - GLADIS), the Road-Accident Location Map and Analysis Network (Verkehrs-Unfall-Lage-Karten und Analyse-Netzwerk-VULKAN), the Brandenburg Expert System for the Analysis and Documentation of Accident-Heavy Route Sections (Brandenburgisches Expertensystem für die Analyse und Dokumentation von unfallauffälligen Streckenabschnitten-BASTa), the Geographic Police Information System for Road accidents (Geografisches Polizeiliches Informationssystem für VerkehrsunfälleGEOPOLIS V) or the widely distributed Topographical Electronic Accident-Type Map (Elektronische Unfalltypensteckkarte-EUSka) [37]. 
In summary, neither reliable specifications for OEM (Original Equipment Manufacturers) mass production solutions ready for market nor concrete information on the functional limits of highly and fully automated driving are currently available. To date, therefore, numerous assumptions have had to be made in forecasting potential safety benefits. Reliable data is also lacking on market launch and penetration. Thus today's projections of potential safety benefits, based on accident data, only have limited validity. It is hence recommended to combine in-depth accident data collections (e.g. GIDAS) with all worldwide available accident data collections and analyzes, traffic simulations, related weather information and vehicle operation data (see Fig. 17.5).

The learning curve in Fig. 17.6 shows the increase of available real world data before and after market launch of automated vehicle functions. To identify relevant critical scenarios the author recommends monitoring and analyzing all available data of automated functions regularly. These provide knowledge for sensor simulation, classifications and decision strategies of future automated vehicles.



Fig. 17.5 Recommended procedure with worldwide relevant test scenarios from around the world based on comprehensively linked-up geographically defined accident, traffic, weather- and vehicle operation data collections pertaining to human and machine perception (see Fig. 17.8). Image rights: Author 


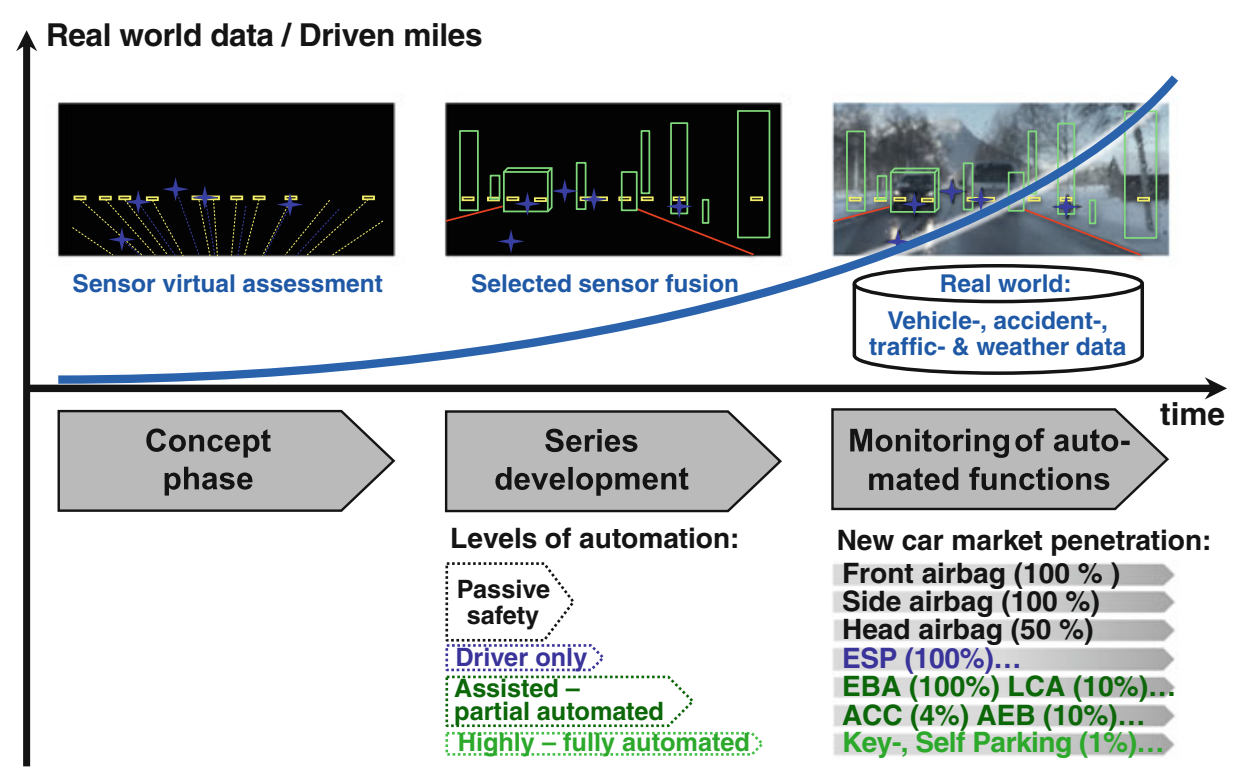

Fig. 17.6 Learning curve increase of available real world data before and after market launch of automated vehicle functions to identify relevant critical scenarios for sensor simulation, classifications and decision strategies (see Fig. 17.8). Image rights: Author

\subsection{Potential Safety Benefits / Risks and Impacts on Testing}

\subsubsection{Human Error and Technical Failure in Full Automation}

Presuming that most accidents are caused by human error (see Sect. 17.5.2.2) it would then be almost possible to realize "Vision Zero", given fault-free fully automated vehicles. However, technical failure and technical limits are still to be expected-especially in fully automated self-driving vehicles.

The left side of Fig. 17.7 shows the statistical cause-of-accident distribution, based on the GIDAS accident database. This accident data show that "human error", at $93.5 \%$, is the main risk of road accidents. The impact of factors involving driving conditions or the environment - road surface quality or weather, for instance - is relatively low according to the statistics, at $4.6 \%$, as is technical failure at $0.7 \%$ [38].

During fully automated driving sections, the number of accidents caused by driver error is ruled out completely. The "technical failure" category could become proportionally larger, with the new technical risks of fully automated driving. This will lead to the public giving it greater attention (see Fig. 17.7). 


\section{Failures today}

\section{Future failures}

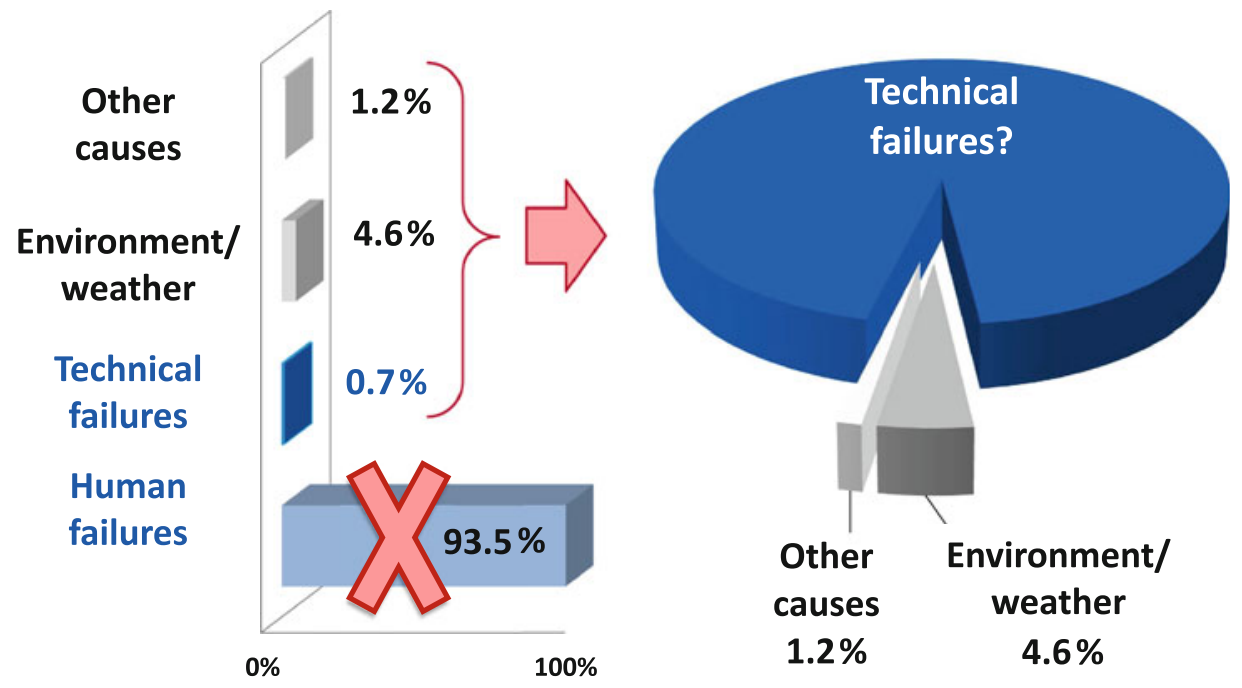

Fig. 17.7 Today $93.5 \%$ of accidents results from human error. With full automation, there would be no more human error. However, the proportion of technical faults may be perceived considerably enlarged in future. Source GIDAS. Image rights: Author

Further assessment and overcoming of human failure-processes in real traffic situationsin addition to worldwide relevant test scenarios based on comprehensively linked up geographically defined accident, traffic, weather, and vehicle operation data collections (see Sect. 17.4.3, Figs. 17.5 and 17.6) -will support virtually traffic simulations for safe development, tests and validation of automated vehicles in the future [39].

\subsubsection{Potential Safety Benefits-Human and Machine Performance}

Vehicles' road safety today essentially depends on the performance of humans supported by safety-enhancing systems. Fully automated vehicles will only rely on the capabilities of machines. Depending on the degree of automation, technical systems will replace humans' perceptions, experience, judgment and capacity to react. Both the potential safety benefits and risks of increasingly automated vehicle guidance result from the various strengths and weaknesses of humans and machines.

Machines, for example, cannot react to unknown situations or interpret the movements of children (see Chap. 20). In comparison, humans can be inattentive, judge distances and speeds badly and their eyes only see a restricted field of vision [29]. 


\subsubsection{Machine Versus Human Perception Limits and Consequences for Testing}

To illustrate the limited performance of technological perception compared to that of humans, a heavily simplified model of currently used sensor technologies is described below. Sensors are needed for a vehicle to be able to collect information about its environment, and are classifiable according to their physical measuring principle. The automobile sector mainly uses radar, lidar, near and far infrared, ultrasound sensors, and cameras. The upper and center image of Fig. 17.8 show simplified and color-coded the limited machine perception of individual measuring principles. Compared with this, the lower image superimposes all these above-named measurements onto what humans perceive among difficult light- and weather conditions (sun, backlight, wet road surface, spray/splashing water, icing/contamination of windshield/sensors, road markings only partially visible). Close investigation reveals that the lefthand radar reflection point (blue) is a false detection, caused by a reflection in the opposite lane (see [40, 41]).

Figure 17.8 illustrates that the outcome of machine perception and interpretation of complex traffic situations continues to present development engineers with considerable technical challenges. These include detecting static and dynamic objects, physically

Fig. 17.8 Machine versus human perception (upper image radar in blue with lidar in yellow, center image addition with camera-image processing in green and red, lower image overlay machine with human perception). Image rights: Author
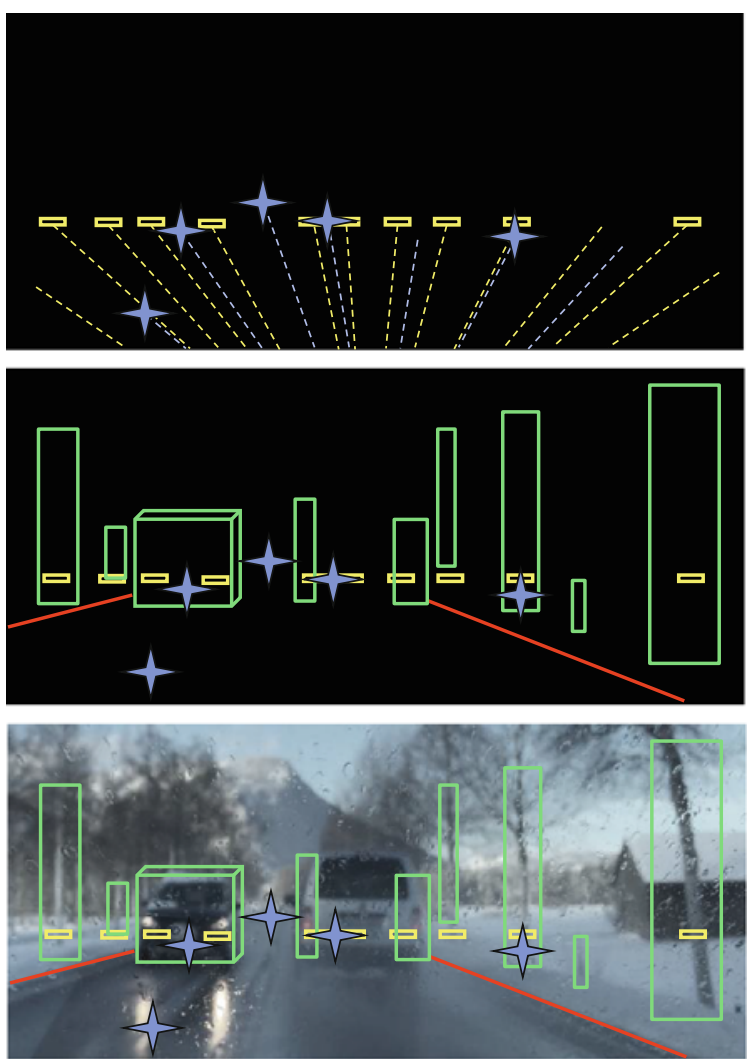
measuring them as accurately as possible, and allocating the correct semantic meaning to the detected objects (see Chap. 20).

Difficult light- and weather conditions challenge human and machine perception in real traffic situations. For this purpose area-wide accident data analyzes (see Sect. 17.4.3.2) are able to indicate temporally and geographically related accident black spots. To analyze scenarios considering reduced visibility due to fog, rain, snow, darkness and glare from sun or headlights, the author carried out a fist-of-its-kind area-wide accident study in cooperation with Christian Erbsmehl from Fraunhofer Institute for Traffic and Infrastructure Systems (IVI) in Dresden. One finding of the case-by-case analysis was that in $95 \%$ of all cases no evasive actions to avoid accidents were documented. Only in $1 \%$ of the cases drivers were able to reduce the consequences of a collision by evasive maneuvers. Other evasive maneuvers failed (4\%). Figure 17.9 presents results of this study with relevant geographical accident scenes for virtual, proofing ground, and field tests of automated vehicles covering all police reports in Saxony from the years 2006 to 2014.

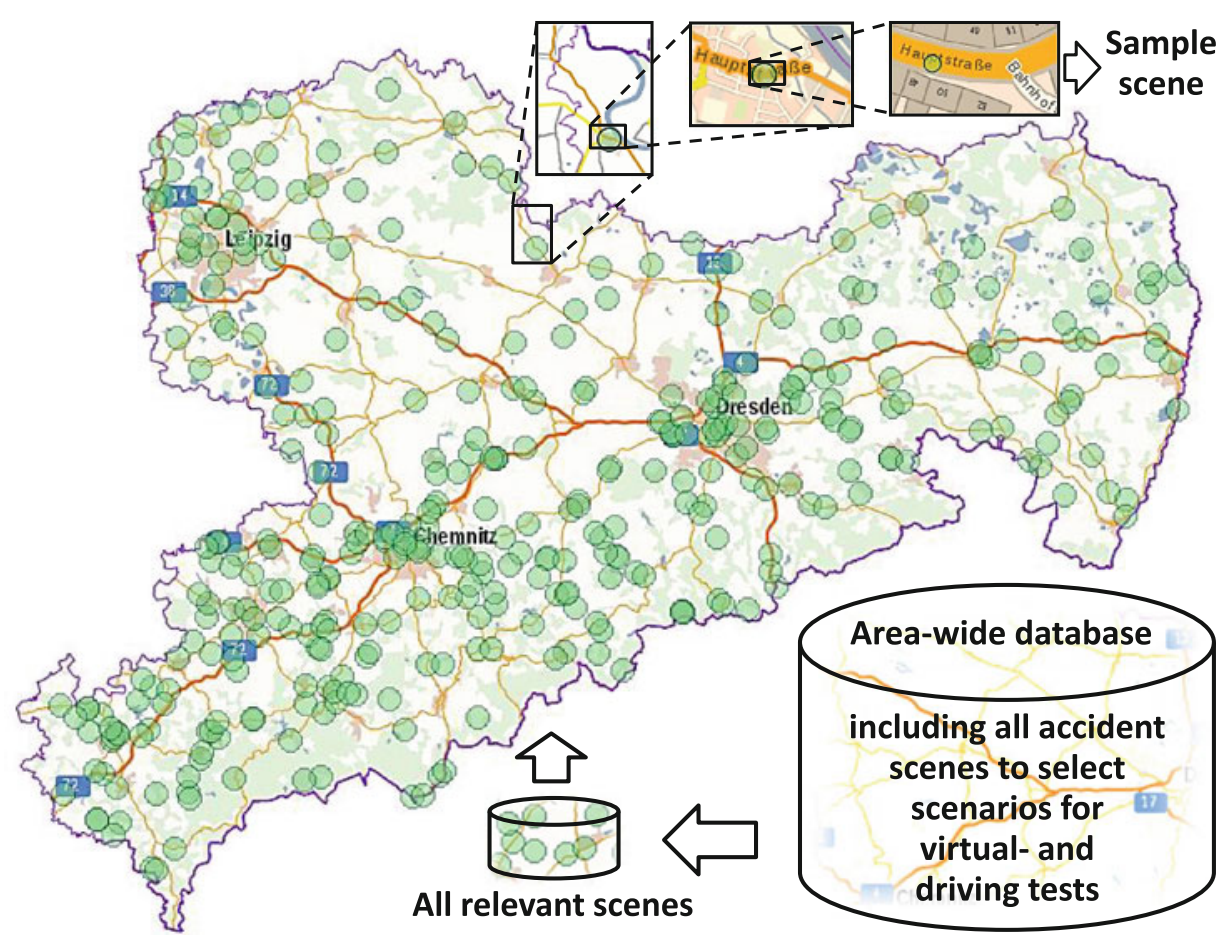

Fig. 17.9 Area-wide geographically related traffic accident scenes with difficult weather conditions and reduced visibility for human and machine perception (Geographical data (C) state-owned enterprise geo basic information and measurement Saxony 2015). Image rights: Author 


\subsubsection{Human Error Versus Machine Incertitudes}

Advancing vehicle automation of the main driver tasks result in new research questions. Attentive and vigilant drivers have substantial skills to deescalate dangerous traffic situations. Human's capabilities provide significant input for traffic safety today. Differentiated potential-benefit estimates would need to compare the performance of humans and machines. Especially take-over situations between driver and machine involve new challenges for design and validation of human-machine interaction. Initial tests at the professorial chair of Klaus Bengler, professor for ergonomics at the Technical University of Munich (TUM) demonstrate relevant ergonomic design requirements which will be continued [42].

Fundamental correlations between automation and human performance can be evaluated by many methods. It is possible to identify the probability of a road accident by the use of a fault tree. Amongst others the probability includes human failure, inappropriate behavior and the existence of a conflicting object [43]. The choice of actions to avoid a collision is greater if the potential road accident is less imminent.

The evaluation of driver behavior requires observations for a longer period. Regarding human failures analyzing the perception process chain provides in-depth knowledge. Such analyzes draw on evaluations of psychological data from road accidents [44]. In terms of interdisciplinary accident analyzes, an error classification of five categories has been approved by practical experience in accident research. This five-steps method is a further development of ACASS (Accident Causation Analysis with Seven Steps). It was developed jointly with GIDAS along the lines of the seven-step principle by Jens Rasmussen, former system safety and human factors professor in Denmark, a highly influential expert within the field of safety science, human error, risk management and accident research [45]. Using the five-steps method it is possible to identify human errors, define the time during the perception process from accessing the information to operation, and to evaluate the particular type of error (see Fig. 17.10). The associated questions concern: Information Access (was the relevant information of the traffic-situation objectively accessible to the driver? Was the field of vision clear?), Information Reception (did the driver observe the traffic situation properly and perceive/detect the relevant information subjectively?), Data Processing (did the driver correctly interpret the traffic situation according to the available information?), Objective Target (did the driver make a decision appropriate to the traffic situation?), and Operation (did the driver carry out his or her decision into operation properly?).

Using this classification, the accident analysis shows that the predominant sources of human error lie in Information Access and Reception (see Fig. 17.10, [25, 46]).

For machine perception, Klaus Dietmayer, professor in Ulm at the Institute of Measurement, Control, and Microtechnology, Expert for Information fusion, Classification, Multi-Object Tracking, Signal processing and Identification (see Chap. 20) names three essential domains of incertitudes corresponding to human Information Access as well as Data Processing. These three are: firstly State-, secondly Existence-, and thirdly Class uncertainty. All three have a direct impact on machine performance. If the uncertainties in 


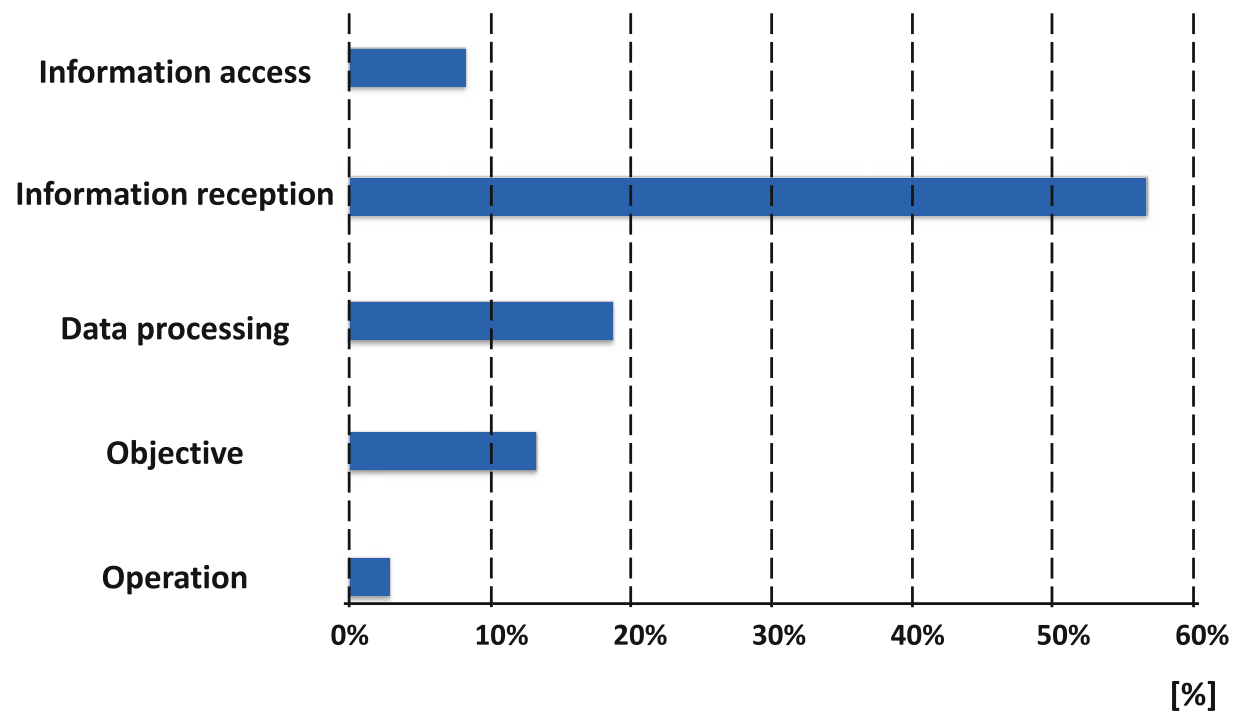

Fig. 17.10 Distribution of human error in road traffic (see [25, 46]). Image rights: Author

these areas increase beyond a yet to be defined "tolerable limit", errors in the automatic vehicle guidance can be expected. In terms of making forecasts, currently only an indication of trends is possible.

While the currently known methods for estimating state and existence uncertainties do not enable a current estimation of the capability of the machine perception, in principle it is not possible to predict degeneration in the capability of individual sensors or even a failure of components. (see Chap. 20)

\subsubsection{Potential Safety Benefits of Fully Automatied Vehicles in Inevitable Incidents}

When analyzing the potential safety benefits of fully automated vehicles, it is also important to consider persistent risks in the area of complex traffic situations and today's known inevitable incidents. These include accidents at poorly visible and unclear intersections or behind visual obstructions. In a study of individual cases as part of a doctoral thesis at the University of Regensburg, visual obstruction was identified as a contributory cause in $19 \%$ of all cases [44]. Examples include trees, bushes, hedges, and high grass. Obstructions for instance may also be the cause of an accident if a child is running out suddenly and unexpectedly in front of a car from between parked vehicles or a yard entrance.

This especially includes errors in the sequences of the perception process, in the accessing and reaches its limits. 
Due to the large number of possible and non-predictable events, especially the reactive actions of other road users, the uncertainties increase so strongly after around $2 \mathrm{~s}-3 \mathrm{~s}$ that reliable trajectory planning is no longer possible on this basis. (see Chap. 20)

Therefore experience-based, internationally valid guidelines with virtual simulation methods for testing and verification of automated vehicles and final testing of the overall system limits in a real environment are recommended. This includes interaction tests with control algorithms and performance verification of real sensors in real traffic situations, particularly at the time just before a collision [47, 48].

\subsection{Conclusion and Outlook}

The findings from road accident research confirm: human failure is the main cause of road accidents. This especially includes errors in the sequences of the perception process, in the accessing and reception of information.

In order to estimate the potential safety benefits of highly and fully automated vehicles from accident data, a sophisticated comparison of the overall performance of humans and machines is required. This, however, will only be possible when precise knowledge is available concerning the functional characteristics and technical limits of developments planned for mass production.

Statistically verified expert assessments have already proven the potential benefits of future safety-supporting vehicle- and driver assistance systems. Even before development has started, for instance, potential benefits can be estimated, and car manufacturers, due to the analysis and evaluation of road accidents, can also fulfill their product monitoring obligations.

Overall, the results of road-accident analyzes today verifiably show that automating driving tasks from the "driver only", "assisted", up to "partially automated" driving categories are key technologies in contributing to minimizing the consequences of human failure.

Forecasts for highly and fully automated vehicles, generated using traffic accident data, only give results based on numerous assumptions. A forecast of fully automated vehicles' potential safety benefits came from a first Daimler accident-research appraisal that is based on several expert assumptions. According to Daimler's estimates, practically complete elimination of accidents is possible by 2070 - assuming successful market penetration. However, only accidents triggered by cars were looked at, and no consideration was given to physical limits and potential technical defects. This appraisal is thus based on some assumptions still to be refined and validated in a more detailed fashion in the future.

Above all, current forecasting is still made difficult by technical challenges. Perceiving and interpreting complex traffic situations, in particular, faces considerable technical challenges for development engineers. Furthermore, human performance is often underestimated. Assistance and partly automated systems essentially are able to compensate for weaknesses in human capacities according to findings from road-accident analyzes. 
They can increase safety in routine human driving situations with supervision, warnings and lateral or longitudinal support. To further reduce the numbers of road accidents, driverless vehicles, on the other hand, at least must first match the driving skills of an attentive human driver, supported by assistance and partly automated systems, considering a series development. Only when these technical barriers have been overcome, can a large-scale rollout of marketable fully automated vehicles be expected.

In summary, the following issues limit the validity of the potential safety benefit forecasts from "driver-only" to fully automated vehicles and will have impact for testing:

- The potential safety benefits stated for levels of automation so far (from driver-only to advanced functionalities) should be judged and used with care, depending on the data used. The validity and forecasting reliability of the data material both depend on the selection and evaluation of available parameters.

- Various approaches to evaluating potential benefits are to be compared with each other under expert consideration. Areas of action show the ideal maximum of possible preventable road accidents. In contrast to this is the actual identifiable efficiency, which is considerably lower.

- The validity of evaluation methods can vary greatly: it makes a significant difference whether an experienced accident reconstructor or analyst together with experts who have participated in all development processes of the current systems - in consultation with medics and psychologists - are involved or not. Such multi-layered background information allows him or her to get a complete overview of a complex accident incident and reconstruct or analyze it more precisely than a colleague without this detailed knowledge.

- There are often many overlapping areas of action within and between analyzes of potential benefits reducing the overall area of action.

- To obtain further findings for the development and design of safe automated vehicles (see Chap. 28), existing in-depth surveys of severe road accidents involving personal injury (e.g. GIDAS) should be combined with available area-wide accident collision data, digital geographic mappings, weather data and virtual traffic simulations (see Chaps. 15 and 16).

- Starting from the level highly automated and beyond, persons involved in an accident have - temporarily at least - no responsibility for the controllability of the vehicle. Measures to reduce risks and guarantee the functional safety of electrical and/or electronic systems are thus of prime importance.

- Fully automated vehicles' degree of efficiency cannot currently be precisely quantified, as numerous technical and market-specific factors are still not known in detail. The evaluation of automated safety functions has to consider all possible system responses: True positive (or negative) and false positive (or negative).

- It may be assumed that individual accident scenarios may still arise as a result of increased degrees of automation, right up to full automation in spite of a 
rule-consistent way of driving. This applies, for instance, to physical driving limits or time-critical situations, such as a child running suddenly in front of a vehicle.

- Area-wide accident analyzes provide relevant scenarios for testing and verification of automated vehicles including virtual simulation methods, but final testing of the overall system limits in a real environment will not be completely eliminated.

The potential safety benefits of fully automated vehicles are finally also based on the assumption that over $90 \%$ of today's road accidents can be put down to human error. Even if the technology of driverless cars never reaches $100 \%$ perfection, and a few as yet unknown accident scenarios arise as a result, the vision of area-wide driverless-vehicle use in road traffic appears to promise a socially desirable benefit. Research activities that make use of interdisciplinary experts working on vehicle automation should therefore be promoted and strengthened. It is recommended to combine in-depth accident data with all worldwide geographically defined accident data collections, related weather, traffic, and vehicle operation data information taking into account data protection measures. This will lead to actual safety benefits and statistically relevant scenarios for development including validation or testing of automated driving pertaining to machine versus human perception.

Open Access This chapter is distributed under the terms of the Creative Commons Attribution 4.0 International License (http://creativecommons.org/licenses/by/4.0/), which permits use, duplication, adaptation, distribution and reproduction in any medium or format, as long as you give appropriate credit to the original author(s) and the source, a link is provided to the Creative Commons license and any changes made are indicated.

The images or other third party material in this chapter are included in the work's Creative Commons license, unless indicated otherwise in the credit line; if such material is not included in the work's Creative Commons license and the respective action is not permitted by statutory regulation, users will need to obtain permission from the license holder to duplicate, adapt or reproduce the material.

\section{References}

1. Bengler K, Flemisch F (2011) Von H-Mode zur kooperativen Fahrzeugführung - Grundlegende Ergonomische Fragestellungen, 5. Darmstädter Kolloquium: kooperativ oder autonom? Darmstadt

2. Bengler K, Dietmayer K, Färber B, Maurer M, Stiller C, Winner H (2014) Three Decades of Driver Assistance Systems: Review and Future Perspectives, IEEE Intelligent Transportation System Magazine, ISSN 1939-1390, Volume 6, Issue 4, pp. 6-22, New York, NY

3. Katzourakis D, Olsson C, Lazic N, Lidberg M (2013) Driver Steering Override Strategies for Steering based Active Safety Systems, In: FAST-zero 2013 - Second International Symposium on Future Active Safety Technology toward zero-traffic-accident, Nagoya

4. Statistisches Bundesamt (2014) Destatis, Zahlen und Fakten, Wiesbaden

5. Kramer F (2013) Integrale Sicherheit von Kraftfahrzeugen: Biomechanik - Simulation Sicherheit im Entwicklungsprozess, Vieweg Teubner, Wiesbaden

6. Gasser T, Arzt C, Ayoubi M, Bartels A, Bürkle L, Eier J, Flemisch F, Häcker D, Hesse T, Huber W, Lotz C, Maurer M, Ruth-Schumacher S, Schwarz J, Vogt W (2012) Rechtsfolgen zunehmender Fahrzeugautomatisierung, Wirtschaftsverlag NW, Berichte der Bundesanstalt für Straßenwesen F83, Bergisch Gladbach 
7. National Highway Traffic Safety Administration - NHTSA (2013) Preliminary statement of policy concerning automated vehicles, Washington, DC

8. Society of Automotive Engineers - SAE international (2014) Levels of driving automation for on road vehicles, Warrendale, PA

9. National Highway Traffic Safety Administration NHTSA (2014) Fatality Analysis Reporting System (FARS), Washington, DC

10. Amoros E, Brosnan M, Wegman F, Bos N, Perez C, Segui M, Heredero R, Noble B, Kilbey P, Feypell V, Cryer C (2009) Reporting on Serious Road Traffic Casualties, International Traffic Safety Data and Analysis Group - IRTAD, Organisation for Economic Co-operation and Development (OECD), International Transport Forum, Paris

11. Zobel R, Winkle T (2014) Personal communication, Wolfsburg u. Braunschweig

12. Schubert A, Erbsmehl C (2013) Simulation realer Verkehrsunfälle zur Bestimmung des Nutzens für ausgewählte simTD-Anwendungsfälle auf Basis der GIDAS-Wirkfeldanalyse - zur Darstellung eines maximal anzunehmenden Wirkfeldes - von Winkle T, Mönnich J, Bakker J, Kohsiek A (2009), Forschungsbericht simTD, gefördert von den Ministerien BMWI, BMBF, BMVBS, Berlin

13. Burg H, Moser A (2009) Handbuch Verkehrsunfallrekonstruktion, 2. Auflage, Vieweg Teubner, Wiesbaden, PC-Crash 11.0 Technical Handbook, http://www.pc-crash.com, http://www.dsd.at

14. O'day J (1986) Remarks about U. S. Accident Investigation Programs FARS und NASS. In: Bierau D, O'day J, Grush E, Erfassung und Auswertung von Straßenverkehrsunfalldaten, Forschungsvereinigung Automobiltechnik, Schriftenreihe 54, pp. 29-31, Frankfurt (Main)

15. Matthaei R, Reschka A, Rieken J, Dierkes F, Ulbrich S, Winkle T, Maurer M (2015) Autonomous Driving, In: Winner H, Hakuli S, Lotz F, Singer C (Eds.) Handbook of Driver Assistance Systems, pp. 1519-1556, Springer International Publishing, Switzerland

16. Hummel T, Kühn M, Bende J, Lang A (2011) Fahrerassistenzsysteme - Ermittlung des Sicherheitspotenzials auf Basis des Schadengeschehens der Deutschen Versicherer, Gesamtverband der Deutschen Versicherungswirtschaft e. V. Forschungsbericht FS 03, Berlin

17. Unger T (2013) ADAC Unfallforschung - Fallverteilung, Datenerhebung, Auswertungen, Landsberg (Lech)

18. Schittenhelm H, Bakker J, Bürkle H, Frank P, Scheerer J (2008) Methods for analyzing the efficiency of primary safety measures based on real life accident data, ESAR 2008, Hannover

19. Koltze K, Souchkov V (2011) Systematische Innovation: TRIZ-Anwendung in der Produktund Prozessentwicklung, Hanser, Munich, Vienna

20. Duden (2014) Die deutsche Rechtschreibung, Bibliographisches Institut, 23. Auflage, Mannheim

21. Daimler AG Communications (2011) Der Weg zum unfallfreien Fahren, COM/M 5836/1635/00/0511, Stuttgart

22. Langwieder K, Gwehenberger J, Hummel T (2003) Benefit Potential of ESP in Real Accident Situations involving Cars and Trucks, 18. International ESV-Conference, Nagoya

23. Zobel R, Friedrich H, Becker H (2000) Accident Research with Regard to Crash Avoidance, Transactions/Vehicle Safety 2000 Conference, London

24. Hörauf U, Buschardt B, Donner E, Graab B, Winkle T (2006) Analyse von Verkehrsunfällen mit FAS Potenzialeinschätzung am Beispiel des FAS Lane Departure Warning. In Tagung Aktive Sicherheit 2006, Technische Universität München, Lehrstuhl für Fahrzeugtechnik, Munich

25. Chiellino U, Winkle, T, Graab B, Ernstberger A, Donner E, Nerlich M (2010) Was können Fahrerassistenzsysteme im Unfallgeschehen leisten? In: Zeitschrift für Verkehrssicherheit 3/2010, TÜV Media GmbH, pp. 131-137, Cologne 
26. Donner E, Winkle T, Walz R, Schwarz J (2007) RESPONSE 3 - Code of Practice für die Entwicklung, Validierung und Markteinführung von Fahrerassistenzsystemen (ADAS). In Technischer Kongress 2007, Verband der Automobilindustrie (VDA), pp. 231-241, Sindelfingen

27. Becker S, Schollinski H-L, Schwarz J, Winkle T (2003) Introduction of RESPONSE 2, EU Projekt. In: Maurer M, Stiller C, Herausgeber, 2. Workshop Fahrerassistenzsysteme - FAS, Leinsweiler

28. Becker S, Mihm J, Brockmann M, Donner E, Schollinski H-L, Winkle T, Jung C, Dilger E, Kanz C, Schwarz J, Bastiansen E, Andreone L, Bianco E, Frost F, Risch A, Eegher van G, Servel A, Jarri P, Janssen W (2004) Steps towards a Code of Practice for the Development and Evaluation of ADAS, RESPONSE 2, European Commission Public Report, Project Deliverable D3, Brussels

29. Knapp A, Neumann M, Brockmann M, Walz R, Winkle T (2009) Code of Practice for the Design and Evaluation of ADAS, Preventive and Active Safety Applications, eSafety for road and air transport, European Commission Project, Brussels

30. Association for the Advancement of Automotive Medicine (2005) The Abbreviated Injury Scale (AIS) Update 2008, Barrington, IL

31. International Organization for Standardization (ISO), ISO 26262-3 (2011): Road Vehicles Functional safety

32. Busch S (2005) Entwicklung einer Bewertungsmethodik zur Prognose des Sicherheitsgewinns ausgewählter Fahrerassistenzsysteme, Fortschritt-Berichte VDI, Reihe 12, Nr. 588, VDI Verlag $\mathrm{GmbH}$, Düsseldorf

33. Klanner F (2008) Entwicklung eines kommunikationsbasierten Querverkehrsassistenten im Fahrzeug, Dissertation, Darmstadt

34. Unselt T, Schöneburg R, Bakker J (2013) Insassen und Partnerschutz unter den Rahmenbedingungen der Einführung autonomer Fahrzeugsysteme, In: 29. VDI/VW-Gemeinschaftstagung "Automotive Security", Wolfsburg

35. Schubert A, Erbsmehl C, Hannawald L (2012) Standardised Pre-Crash-Szenarios in digital format on the basis of the VUFO Simulation, Dresden

36. Helmer T (2015) Development of a Methodology for the Evaluation of Active Safety using the Example of Preventive Pedestrian Protection, Springer Theses, Springer International Publishing Switzerland

37. Dick R (2011) Die Polizeilichen- Online- Informationssysteme in der Bundesrepublik Deutschland, Books on Demand GmbH, Norderstedt

38. GIDAS - German In-Depth Accident Study - Unfalldatenbank, Dresden, Hannover

39. Kompass K, Helmer T, Wang L, Kates R (2015) Gesamthafte Bewertung der Sicherheitsveränderung durch FAS/HAF im Verkehrssystem: Der Beitrag von Simulation. In: Klaffke W (Eds.) Kompass K, Fahrerassistenz und Aktive Sicherheit: Wirksamkeit Beherrschbarkeit - Absicherung, Haus der Technik Fachbuch Band 137, Expert Verlag, Renningen

40. Becker S, Brockmann M, Jung C, Mihm J, Schollinski H-L, Schwarz J, Winkle T (2004) ADAS - from Market Introduction Scenarios towards a Code of Practice for Development and Evaluation, Final Report, RESPONSE 2 - European Commission, Public Report, Brussels

41. Donner E, Schollinski H-L, Winkle T, Jung C, Dilger E, Kanz C, Schwarz J, Bastiansen E, Andreone L, Becker S, Mihm J, Jarri P, Frost F, Janssen W, Baum H, Schulz W, Geissler T, Brockmann M (2004) Methods for Risk-Benefit-Analysis of ADAS: Micro Perspective and macroscopic socioeconomic evaluation, RESPONSE 2, European Commission Public Report, Project Deliverable D2, Brussels 
42. Bengler K (2015) Grundlegende Zusammenhänge von Automatisierung und Fahrerleistung. In: Klaffke W (Eds.) Kompass K, et.al. Fahrerassistenz und Aktive Sicherheit: Wirksamkeit Beherrschbarkeit - Absicherung, Haus der Technik Fachbuch Band 137, Expert Verlag, Renningen

43. Reichart G (2000) Menschliche Zuverlässigkeit beim Führen von Kraftfahrzeugen, TU München, Maschinenwesen, Lehrstuhl für Ergonomie, Dissertation, Munich

44. Gründl M (2006) Fehler und Fehlverhalten als Ursache von Verkehrsunfällen und Konsequenzen für das Unfallvermeidungspotenzial und die Gestaltung von Fahrerassistenzsystemen, Dissertation, Regensburg

45. Rasmussen J (1982) Human errors: a taxonomie for describing human malfunction in industrial installations. Journal of Occupational Accidents 4, pp. 311-333, Elsevier Scientific Publishing Company, Philadelphia, PA

46. Weber S, Ernstberger A, Donner E, Kiss M (2014) Interdisziplinäre Unfallforschung - ein Zusammenschluss von Technik, Medizin und Psychologie zur Steigerung der Verkehrssicherheit. In: Verkehrsunfall und Fahrzeugtechnik (VKU), Springer Automotive Media, 2/2014, pp. 61-65, Wiesbaden

47. Schöner H-P, Hurich W, Luther J, Herrtwich R G (2011) Coordinated Automated Driving for the Testing of Assistance Systems, ATZ - Automobiltechnische Zeitschrift, Springer Automotive Media, Volume 113, Issue 1, pp. 26-31, Wiesbaden

48. Schöner H-P (2015) Fahrsimulatorgestützte Wirksamkeitsbewertung der Fahrerassistenz-Systeme. In: Klaffke W (Eds.) Kompass K, Fahrerassistenz und Aktive Sicherheit: Wirksamkeit Beherrschbarkeit - Absicherung, Haus der Technik Fachbuch Band 137, Expert Verlag, Renningen 